\title{
Avance preliminar sobre los materiales del s. XIII en Murcia: los resultados del sondeo estratigráfico realizado en la Capilla del Palacio Episcopal
}

\author{
Jesús Bellón Aguilera *
}

\begin{abstract}
RESUMEN
El sondeo estratigráfico realizado en el subsuelo de la Capilla del Palacio Episcopal de Murcia, han permitido el estudio y documentación de todo un conjunto de materiales cerámicos procedentes de niveles estratigráficos sellados. El análisis comparativo de los resultados obtenidos con los datos procedentes de otras excavaciones, supone la posibilidad de elaborar una seriación coherente de los mismos y, a su vez, la necesidad de revisar las propuestas realizadas con anterioridad para las cerámicas de los SS. XII y XIII en Murcia.
\end{abstract}

PALABRAS CLAVE: Estratigrafía. Cerámicas. Análisis. Revisión.

\section{INTRODUCCIÓN}

Los planteamientos preliminares del presente trabajo comenzaron hace algo más de tres años, cuando realizamos la primera campaña de excavaciones en el yacimiento arqueológico de "El Pocico II' (Cañadas de San pedro, Murcia) una alquería localizada en el territorio que, desde Zeneta hasta Sucina, se conoce como Campo de Murcia (MOLINA, 1989), y en cuya franja oriental se constituyó la frontera entre Castilla y Aragón en el S. XIV. La existencia de esta frontera no sólo es perceptible en la toponimia de la zona (GARRIDO I VALLS,

\section{RESUMÉ}

Les fouilles d'emergence réalisées a la Chapelle du Palais Episcopale á Murcia, on mis a jour tout un ensemble de matériaux céramiques qu'on été trouves au des niveaux stratigraphiques fermées. L'analyse et comparaison des résultées trouvées avec les dates d'autres fouilles permettrent la possibilité de faire une sériation des mémes et il suppose, aussi, la nécessité de faire une révision méthodique des diverses propositions réalisées jusqu'á maintenant a propos de la céramique du Xlle" et Xlleme siécles á Murcia.

MOTS DE RÉFÉRENCE: Stratigraphie. Céramigues. Analyse. Révision.

1997), sino que es evidente en el registro arqueológico, tanto en lo que se refiere a los materiales, como a la propia ocupación del territorio, para el que todas las evidencias indican un abandono generalizado de la mayoría de los núcleos habitados desde finales del S. XIII, hasta la práctica despoblación de la zona en la primera mitad del S. XIV, iniciándose un tímido intento de colonización del territorio a mediados del $\mathrm{S}$. XV (MOLINA, op. cit.) que parece haber fraguado definitivamente en el S. XVII.

El principal problema con el que nos encontrábamos radicaba en la caracterización crono-

* Arqueólogo, 
lógica de los materiales; a simple vista, éstos podían ser fácilmente encuadrados entre los SS. XII-XIII... Al menos, esta era la cronología más generalizada en la bibliografía especializada, tan impregnada, por otra parte, de ese mecanicismo empirista que basa el conocimiento en la experiencia y que, en su versión vulgarizada, supone que cuanto mayor sea la experiencia, es decir, cuantos más datos se hayan acumulado, mayor será el conocimiento. Esta ecuación es falsa. En primer lugar, porque el que haya más datos no implica que haya más conocimiento, como el hecho de que haya más moneda en circulación no implica que haya más riqueza. En segundo lugar, porque el campo de la experimentación es sólo la parte visible de lo que, como diría Althusser, permanece oculto, es decir de lo que no se ve, que es precisamente el lugar donde, siguiendo con Althusser y Foucault, se conoce, re-conoce o, sencillamente (y en la mayoría de los casos), des-conoce algo. Para nosotros, el problema de las cerámicas estaba íntimamente ligado al del conocimiento real de nuestro objeto de estudio, ya que la simple variación cronológica de los restos exhumados de la primera mitad del S. XIII a la segunda mitad del mismo siglo implicaba cambios radicales en la naturaleza y características de nuestro objeto, lo que podía inducirnos a errores interpretativos, como finalmente sucedió (BELLÓN AGUILERA, J; MARTíNEZ SALVADOR, C.; 1999). Por desgracia, la dinámica impuesta por nuestro trabajo como profesionales liberales de la arqueología nos obligaba, por un lado, a difundir hipótesis de trabajo no demasiado maduras $y$, por otro, a culminar adecuadamente el proceso de investigación que iniciamos hace tres años y del que, a la espera casi inmediata de sus resultados definitivos, este trabajo constituye, paradójicamente, uno de sus primeros resultados.

Las fuentes parecen sugerir la ubicación en el solar del Palacio Episcopal de al menos una parte de la Dar al-Sarif (FUENTES Y PONTE, 1872), palacio que, por lo tanto, estaría ya fuera del perímetro del Alcázar Mayor, según demuestran los interesantes resultados de las últimas excavaciones arqueológicas realizadas en la zona (BERNABÉ GUILLAMÓN et alii, 1994), si bien en una zona lindera con la muralla exterior de la madina cuyo trazado discurre por el subsuelo bajo la cimentación de la fachada $S$ del Palacio, según confirman los sondeos efectuados al respecto por la empresa Geocisa durante la presente campaña de restauración del Palacio.

El estudio pormenorizado de la secuencia estratigráfica ha sido objeto de un trabajo reciente, por lo que aquí me limitaré a exponer los resultados globales (BELLÓN AGUILERA, 200I).

La comparación entre el análisis final de las unidades estratigráficas y los resultados obtenidos por el estudio de los materiales, permiten resumir la cronología propuesta para la secuencia estratigráfica obtenida como sigue:

- UE- II6: S. XX, año 1992

- UUEE- 100, 101, 102, 103 y 104: Primera mitad s. XVIII

- UE- I | 3: Finales del s. XVI, principios del s. $\mathrm{XVII}$

- UUEE- I09, I I0 y I I I: Finales del s. XIII, principios del s. XIV

- UUEE- I 2I, UE- 123 y UE- I 25: Mudéjar. Tercer y último cuarto del s. XIII

- UE-127: Islámico. Segundo y tercer cuarto del s. XIII

- UUEE- 129 y 131: Islámico. Segundo cuarto del s. XIII

- UUEE- 133, 134 y 135: Islámico. Primer y principios del segundo cuarto del s. XIII, finales del s. XII

- UE-|38:Islámico. Primer cuarto del s. XIII, finales del XII

\section{LOS MATERIALES ARQUEOLÓGICOS}

El estudio se ha realizado atendiendo a las unidades estratigráficas en que fueron localizados los materiales. También se han tratado de evaluar las características generales de éstos atendiendo fundamentalmente a las técnicas de producción y considerando operativas, a nivel puramente conceptual, las informaciones 
y datos porcentuales procedentes de la Factura de los materiales y de la Cocción de los mismos. Esta consideración de ambos elementos como operativos conceptualmente merece una explicación, sobre todo, pohque su valor como elementos auxiliares para la caracterización cronológica de los paquetes estratigráficos se ha devaluado en la bibliografía actual en contraste con la década de los ochenta y principios de los noventa. En lo que se refiere a la cocción, pienso que la práctica desaparición de este elemento podría deberse sobre todo a los estudios analíticos que evidencian para Al-Andalus la inexistencia de la oposición clásica entre cocciones oxidantes y reductoras (BAZZANA, 1979) y, por tanto, hacen necesaria la realización de trabajos de investigación específicos cuyo desarrollo está fuera del alcance de la mayoría de los profesionales de la arqueología. Pero, también en mi opinión, el reconocimiento de esta realidad no ha servido en general sino para retraer el uso de los mecanismos cuantitativos tradicionales que hubieran coadyuvado a analizar y explicar el proceso de cambio o desarrollo tecnológico que diferencia los conjuntos cerámicos de los SS VIII al XI de los de los SS XII y XIII. Es por eso que he optado por reintroducir la vieja oposición oxidante/reductora con 'el objeto de obtener los referentes necesarios para poder contrastar las diferentes producciones cerámicas exhumadas, partiendo del reconocimiento de que las sensibles variaciones de color perceptibles a nivel global entre unos conjuntos cerámicos y otros no es el resultado de procesos de cocción más o menos caprichosos sino que obedece a unas lógicas productivas que no conocemos con exactitud. Por tanto, y en el marco propuesto para este estudio, los términos de Cocción oxidante, reductora o mixta funcionan exclusivamente como conceptos epistemológicos, y deben entenderse como categorías "significantes" reproducidas del argot científico tradicional que carecen de sus "significados" originarios.

Algo parecido sucede respecto a la Factura de los materiales. El desarrollo de la investigación arqueológica ha puesto de relieve, cada vez con mayor intensidad, la coexistencia de diversas técnicas productivas independientemente de la cronología global de las producciones (GUTIERREZ, 1996). Así, en un mismo período cronológico coexisten las técnicas de modelado, torno, molde y torneta sin que este dato resulte eficaz si se intenta utilizar como único elemento para la datación de las producciones exhumadas.

El principal inconveniente para el estudio de los materiales de este sondeo lo constituye la escasez y fragmentación del material. A pesar de ello, trataré de proponer algunas cuestiones cronológicas basándome en la comparación de los hallazgos cerámicos de la Capilla del Palacio Episcopal con los realizados en contextos estratigráicos similares procedentes de las excavaciones arqueológicas realizadas, fundamentalmente, en la Región de Murcia y el área del Levante. Para la descripción de las piezas cerámicas, seguiré básicamente las propuestas metodológicas de Bazzana (1979) y Rosselló-Bordoy (1978b).

\section{UE-Superficial}

Los materiales localizados en esta unidad estratigráfica son producto del seguimiento de los trabajos de ejecución de la zanja para la instalación de los tubos de drenaje antihumedad previstos en el Proyecto de Restauración. La apertura manual de esta zanja supuso la exhumación de un conjunto de pequeños cuencos y fragmentos de cuenco que fueron facturados a torno, con cocciones oxidantes y textura compacta (CPE/200 I /SUP/ I y CPE/200 I /SUP/2), de los que no podemos ofrecer una filiación cronológica segura, dadas las características generales del hallazgo y la carencia de referentes bibliográficos para el grupo, si bien es posible pensar que estos ejemplares puedan ser fechados en torno a los ss. XVII y XVIII.

\section{UE- 100}

Sólo se localizaron tres fragmentos cerámicos en esta unidad cuyas características estratigráficas se describen en el apartado correspondiente. Atendiendo a su posición estratigráfica y a las similitudes formales que presentan estos materiales, especialmente el plato (CPE/200I/I00/I), con los localizados en otras excavaciones en Murcia (GARCíA CANO y 
MANZANO MARTÍNEZ; 199I) (JIMÉNEZ CASTILLO, NAVARRO PALAZÓN, COLL CONESA y BARRACHINA; 1997), pienso que la cronología de estos materiales debe ser relacionada con el momento de fundación de la Capilla, es decir; en la primera mitad del s. XVIII.

\section{UE-109}

Se trata de una unidad de relleno y nivelación, de un suelo superior (UE- I05), por lo que los materiales contenidos en el depósito arqueológico deben pertenecer a un horizonte cronológico inmediatamente anterior a la construcción de dicho suelo. Aunque, como es lógico, es factible la subsistencia en el registro arqueológico de materiales más antiguos que podrían distorsionar el análisis del conjunto, cabe destacar la homogeneidad de éste, en el que se observa un predominio absoluto (100\%) de las producciones a torno, distribuido en las formas jarro/a, jarrita y jofaina. Las cocciones son oxidantes para las formas abiertas y para un ejemplar de contenedor de líquidos (jarra) al 50\%, siendo un 33\% del total; por su parte, las cocciones reductoras se reservan preferentemente para las formas cerradas (67\%), debido probablemente a los requerimientos técnicos específicos de cada tipo de producción.

La ausencia de otros elementos de análisis para el conjunto, así como sus propias características. tecnológicas no difieren a grandes rasgos de tos materiales localizados generalmente en los niveles estratigráficos del s. XIII. Por el contrario, la aparente tendencia a la generalización de las cocciones oxidantes, podrían sugerir un horizonte cronológico tardío encuadrable en la segunda mitad de ese mismo siglo.

\section{UE-IIO}

Al igual que en el caso anterior; los materiales localizados en esta unidad estratigráfica se caracterizan por su estado fragmentario, lo que se explica por su inclusión en un paquete de relleno de nivelación similar al anterior.Técnicamente se trata de producciones realizadas mayoritariamente a torno, constituyendo esta técnica el 100\% del material habitual, si bien la presencia de fragmentos de grandes contene- dores (Forma tinaja) y las consabidas características productivas de éstos (MARTÍNEZ RODRIGUEZ y MONTERO FENOLLÓs, 1989) implican una distorsión en las proporciones obtenidas del 17\% para las producciones a mano/torno lento frente al $83 \%$ realizadas a torno.

Los acabados se presentan en tres grandes grupos: a) cubiertas vítreas en melado, b) cubiertas vítreas en blanco, y c) cubiertas vítreas en verde. Especialmente interesante resulta el vidriado del frag. de ataifor CPE/2001//10/2, en melado más oscuro de lo habitual en las producciones normalizadas del s. XIII. Vidriados similares se constatan en los niveles de uso más superficiales de la calle Fricas y del Pocico II (BELLÓN AGUILERA y MARTÍNEZ SALVADOR, 1999b y 1999c), fechables entre el último tercio del s. XIII y los comienzos del s. XIV.

Pero quizás el elemento más significativo de este conjunto cerámico sea el fragmento CPE/200I// /0//2. Facturado a torno, se caracteriza por una pasta de textura compacta-granulosa, con relativamente abundantes desgrasantes minerales múltiples de pequeño tamaño y color grisáceo-negruzco. Descrito en el inventario como marmita, presenta un cuello ligeramente exvasado, borde plano inclinado inclinado al interior (probablemente como soporte para tapadera) y labio biselado recto al exterior. Su diámetro es de 130 mm. Tanto sus características técnicas, como sus características formales remiten a contextos bajomedievales de principios del s. XIV (NAVARRO POVEDA, 1990) (AZUAR RUIZ, 1994) (AZUAR, MARTA y PASCUAL 1998).

La situación estratigráfica de esta unidad, junto a las características técnicas generales y específicas de los materiales analizados y descritos, así como la destacable ausencia en el registro cerámico de las producciones típicas de los talleres de Paterna-Manises, inducen a proponer para este conjunto una cronología centrada entre finales del s. XIII y principios del s. XIV.

\section{UE-I I I}

Lo más destacable del registro cerámico de esta unidad es, sin duda, la coexistencia de dos tipos de marmita: un tipo a) (CPE/200/// //6) 
del que sólo podemos describir un frag. de pared acanalada muy fina, de cocción mixta, facturada a torno, con abundante desgrasante calizo de tamaño muy pequeño y color rojizonegruzco (debido, seguramente, más que a una hipotética cocción mixta a la propia combustión de la pasta por su exposición al fuego) cuyo acabado interior presenta un vedrío verduzco degradado, y un tipo b) (CPE/200I/II I/7) perteneciente a un fondo plano indicado de grosor medio caracterizado por su cocción reductora, y facturado a torno con una proporción relativamente abundante de desgrasantes minerales múltiples de tamaño pequeño y medio, y cuyo color es parduzco, sin que parezca tener otro tipo de acabado interior que el propio alisado de la pieza.

En mi opinión, el primer tipo mantiene similitudes técnicas y formales con los ejemplares más comunes de comunes de marmita que se suelen fechar en el s. XIII, caracterizados por cuerpos de tendencia globular, cuellos troncocónicos y bases convexas (NAVARRO PALAZÓN 199 I) (AZUAR RUIZ, 1985) (AZUAR RUIZ, et alii, 1995). En cuanto al segundo tipo, podría parecer sorprendente la aparición de un ejemplar de estas características en este nivel estratigráfico, pero, en mi opinión, sólo se trata de un ejemplar de cerámica común de cocina vinculable a las producciones "feudales" que sustituyen inmediatamente a las producciones "islámicas" en contextos tardíos de finales del s. XIII, principios del s. XIV en diversos yacimientos de Murcia y Alicante, y se relaciona directamente con el tipo de marmitas localizadas en los niveles de uso del Pocico II (MARTÍNEZ SALVADOR y BELLÓN AGUILERA, 1999c), fechables entre el último tercio del $s$. XIII y los comienzos del s. XIV, y caracterizadas por su base plana indicada, cuerpo piriforme $y$ labio regruesado y exvasado, factura a torno lento/torneta y pastas anaranjadas o pardas con desgrasantes silíceos, calizos y mica dorada (AZUAR, MARTÍ y PASCUAL, 1998).

Como conclusión, y basándonos en razonamientos similares a los descritos para la UE I I 0, podemos establecer para este conjunto cerámico una propuesta cronológica centrada entre finales del s. XIII y principios del s. XIV.

\section{UE-II 3}

Se trata de materiales procedentes del relleno de la fosa de fundación UE- II 2 del pozo séptico UE-I003.

Técnicamente, se trata de formas facturadas a torno, pastas bien decantadas y compactas de color granate 0 pardas, y acabados predominantemente realizados mediante vedríos estanníferos blancogrisáceos de tonos azulados para las formas abiertas y verdes oscuros para contenedores de líquidos (jarros/as) y lebrillos. Entre las formas abiertas destaca la presencia de diversos tipos de plato, los cuencos de base cóncava y las escudillas de asa trilobulada.

A juzgar por la bibliografía consultada (JIMÉNEZ CASTILLO, NAVARRO PALAZÓN, COLL CONESA Y BARRACHINA, 1997) (GARCÍA CANO Y MANZANO MARTÍNEZ, 1991), se trata de materiales encuadrables cronológicamente entre finales del s. XVI y principios del s. XVII, si bien su caracterización definitiva dependerá del trabajo de un especialista.

\section{UE-|2 |}

Al igual que en el caso de la UE-I I0, se trata técnicamente de producciones realizadas mayoritariamente a torno, constituyendo esta técnica el 100\% del material habitual.

Los vidriados se distribuyen en dos grupos: a) vidriados en verde turquesa para la forma ataifor, y b) vidriado en blanco para las formas tapadera y redoma.

En cuanto a las decoraciones, el fragmento CPE/200 I/I2I/3, presenta un estampillada aparentemente poco profundo, aunque muy degradado, mientras que el jarrito/a CPE/200 | / | 2 |/5, cuya pasta blanquecina y acanalada recuerda la de las jarritas esgrafiadas, aparece decorado exclusivamente con dos líneas paralelas en óxido de manganeso, sin que su estado fragmentario permita otro tipo de conclusiones.

Materiales de estas características se documentan habitualmente en los últimos niveles 
de ocupación islámica de Murcia (NAVARRO PALAZÓN, 199 I; BERNABÉ GUILLAMÓN, 1990a; MANZANO MARTÍNEZ, 1987-88), Molina de Segura (SÁNCHEZ GONZÁLEZ, 1990), LorCa (MARTíNEZ RODRÍGUEZ, et alü, 1990), Jijona (AZUAR RUIZ, R. 1985), Aspe (AZUAR RUIZ, R. (Dir.), 1994) O Denla (GISBERT SANTONA, 1992), por lo que podemos proponer provisionalmente una cronología centrada en el segundo tercio del s. XIII.

\section{UE- I 23}

Se trata de producciones facturadas a torno (100\%) y cocciones mayoritariamente oxidantes (62\%, frente a $25 \%$ R y $13 \%$ M), distribuyéndose estas cocciones entre los tipos jarro/a redoma y marmita, para las primeras, jarro/a para las reductoras, y ataifor para las mixtas.

Lo más destacable de esta unidad es la presencia en el mismo paquete estratigráfico de a) marmitas de pasta gruesa, base plana, cuerpo de tendencia troncocónica y borde reentrante (CPE/200 I / | 23/8) similares a las descritas para cronologías de los ss. XI y Xll, si bien están facturadas a torno y con vedrío interior transparente, lo que las acerca a las producciones fechadas a finales del s. XII principios del s. XIII, junto a b) marmitas de pastas mucho más finas, fondo indicado con cuerpo de tendencia globular e igualmente vidriadas al interior con vedrío transparente (CPE/200 I//23/6 y 7) que suelen tener cronologías más tardías centradas en la primera mitad del s. XIII.

Las características descritas de los materiales y su posición estratigráfica, sugieren una cronología que debe ser situada a mediados del s. XIII, aunque su evaluación definitiva depende de su contraste con las cronologías propuestas para los niveles inferiores.

\section{UE- 127}

Se trata de producciones realizadas mayoritariamente a torno. En cuanto a las cocciones, las tipificadas como oxidantes suponen un 34\% del total, frente al $50 \%$ de las reductoras y un 16\% de mixtas, distribuyéndose las oxidantes mayoritariamente entre las formas ataifor, marmita y un solo fragmento de jarrito/a,y reservándose mayo- ritariamente las reductoras para las formas, jarrito/a, jarro/a, anafe y reposadero. En cuanto a las cocciones mixtas, están presentes prácticamente en todos los grupos representados.

Los acabados se presentan en tres grandes grupos: a) cubiertas vítreas en melado, b) cubiertas vítreas en blanco, y c) cubiertas vítreas en verde. Cabe destacar el vidriado en marrón o melado muy oscuro del frag. de ataifor CPE/200 I // 27/6, realizado sólo al interior, lo que suele indicar cronologías tardías centradas en el último tercio del s. XIII, generalizándose este tipo de producciones a finales de este siglo y comienzos del s. XIV.

También es interesante la técnica decorativa del fragmento CPE/200 I/ I27/30, caracterizada por un estampillado poco profundo (en torno a $1 \mathrm{~mm}$ ) con motivos vegetales y que debe ser fechado a mediados del s. XIII.

En cuanto a la forma marmita, todos los fragmentos localizados se corresponden con formas similares a las descritas en el apartado b) correspondiente de la UE-123, con fondos ligeramente convexos, cuerpos de tendencia globular y bordes rectos de tendencia troncocónica o cilíndrica, cocciones oxidantes y pastas finas, que se fechan en la primera mitad del s. XIII.

También se han inventariado diversos fragmentos de jarrito/a con decoración esgrafiada desarrollada (CPE/200I/ I27/9, I0 Y I I). La cronología de estas producciones es problemática, dado su desarrollo desde finales del s. XII y a lo largo de todo el s. XIIII (ROSSELló PONS, 1983), (NAVARRO PALAZÓN, 1986), así como su continuidad en época mudéjar (AMIGUES, MESQUIDA y SOLER, (991). Sin embargo, todo parece indicar que los esgrafiados pertenecientes a los grupos 2 y 4 descritos por Julio Navarro en su trabajo sobre este tipo de cerámicas (NAVARRO PALAZÓN, 1986) se desarrollan, sobre todo, en contextos tardíos centrados en el segundo tercio del s. Xlll,como parece deducirse del mismo hallazgo del pozo de San Nicolás (NAVARRO PALAZÓN, 1991), en el que parecen existir diversas producciones cerámicas cuya cronología estaría comprendida entre el segundo y tercer cuarto del s. XIII, aunque 
la confusa argumentación esgrimida por el autor de la publicación pretenda centrar las producciones en un momento anterior al año 1.243. La ausencia de una metodología de excavación por niveles con el registro sistemático de los grupos cerámicos localizados (como ya sucedió con los materiales del alfar antiguo de San Nicolás (NAVARRO PALAZÓN, 1990), junto a una abundante presencia de paneles decorativos pseudoepigráficos y formas cerámicas muy evolucionadas, indican que al menos una parte importante de los materiales localizados en el pozo de San Nicolás debería ser fechada a mediados del tercer cuarto del s. XIII, lo que coincide tanto con las propias características del hallazgo como con los resultados estratigráficos obtenidos en la excavación realizada por nosotros en el yacimiento El Pocico I I (BELLÓN AGUILERA y MARTíNEZ SALVADOR, 1999a) donde coexisten ejemplares cerámicos tardíos de los tipos "bh" y"be" de Rosselló-Bordoy (1983), con decoración esgrafiada mediante técnicas mixtas como pintado-esgrafiado (ROSELLÓ PONS, 1983) y esgrafiado "total" ("grupos" "2" y "4" de NAVARRO PALAZÓN, 1986a), con ejemplares similares pintados de forma mixta almagra-manganeso, que se documenta en ya en contextos tardíos en Aspe (AZUAR (Ed.), 1994) y Murcia (GALLEGO GALLARDO, 1989).

También se ha documentado la presencia de reposaderos (AMORES LLORET, 1991) (NAVARRO PALAZÓN Y JIMÉNEZ CASTILLO, 1995), que suelen aparecer estratigráficamente asociados a contextos tardíos y de abandono (BERNABÉ GUILLAMÓN, 1990b) relacionables con las consecuencias de los sucesos de 1.264-1.266.

En resumen, y teniendo en cuenta todo lo escrito hasta el momento, proponemos una cronología para este conjunto cerámico centrada entre finales del segundo y comienzos del tercer cuarto del s. XIII.

\section{UE-I 29}

A nivel estadístico, existen pocas variaciones en los resultados obtenidos para esta unidad estratigráfica respecto de las que la anteceden en el registro estratigráfico.
Los acabados son similares a los descritos para la unidad anterior, existiendo cubiertas vítreas en melado y manganeso, cubiertas vítreas en blanco, cubiertas vítreas en verde turquesa y cubiertas transparentes para la forma marmita. Es interesante anotar aquí la abundancia de fragmentos de la forma jarrito/a y jarro/a pintados al manganeso, generalmente motivos geométricos o vegetales, sin que el estado fragmentario del material impida mayores precisiones.

En cuanto a la forma marmita, casi todos los fragmentos localizados se corresponden con formas similares a las descritas para la UE-I27, con fondos indicados ligeramente convexos, cuerpos de tendencia globular y bordes rectos de tendencia troncocónica o cilíndrica, cocciones oxidantes y pastas finas, que se fechan genéricamente en la primera mitad del s. XIII, si bien la forma cazuela ha proporcionado un borde de tipo reentrante, factura a torno y cocción oxidante.

También se han inventariado diversos fragmentos de jarrito/a con decoración esgrafiada desarrollada (CPE/200 I / 129/ 5, 6 y 7).

Teniendo en cuenta las observaciones realizadas a propósito de la UE- 127, y atendiendo a la posición estratigráfica del conjunto cerámico exhumado en esta unidad, se puede pensar en una cronología para este conjunto cerámico centrada a finales del segundo cuarto del s. XIII.

\section{U.E.- | 3 |}

La ausencia de producciones con facturaciones específicas similares a las descritas para las formas tinaja, anafe o tannur, p.e., hacen que los resultados estadísticos, obtenidos para esta unidad estratigráfica lleguen al 100\% para las producciones a torno.

Respecto de los acabados, predominan las cubiertas vítreas en melado, sin que este dato se pueda considerar significativo habida cuenta de la escasez de material vidriado, existinedo también cubiertas transparentes para la forma marmita. Al igual que sucedía en el caso de la UE- 129, inmediatamente anterior a ésta en la secuencia estratigráfica, es interesante des- 
tacar la abundancia de fragmentos de la forma jarrito/a y jarro/a pintados al manganeso, generalmente motivos geométricos o vegetales, sin que el estado fragmentario del material impida mayores precisiones.

En cuanto a la forma marmita, casi todos los fragmentos localizados se corresponden con formas similares a las descritas para la UE- 129 , con fondos indicados ligeramente convexos, cuerpos de tendencia globular y bordes rectos de tendencia troncocónica o cilíndrica, cocciones oxidantes y pastas finas, que se fechan genéricamente en la primera mitad del s. XIII (CPE/200 I/I3 |//3). También se ha inventariado un fragmento de jarrito/a con decoración pintada y esgrafiada desarrollada (CPE/200 ///3 //3).

En resumen, y habida cuenta de las semejanzas existentes entre las producciones de esta unidad y las de su antecesora UE-129, y atendiendo a la posición estratigráfica del conjunto cerámico exhumado, se propone una cronología similar para este conjunto cerámico centrada en el segundo cuarto del s. XIII.

\section{UE- I 33}

El I00\% de los materiales exhumados en esta unidad están facturados a torno, por lo que cabe considerar aquí las observaciones que se hacían a propósito de estos resultados estadísticos para la UE- I 31 . En cuanto a las cocciones, se observa un equilibrio entre las denominadas como oxidantes (52\%) frente a las llamadas reductoras (4l\%), siendo el $7 \%$ el porcentaje relacionado con las cocciones mixtas, dominando el primer tipo de cocciones en las formas ataifor, orza y marmita, y las segundas en las formas jarrito/a.

En cuanto a los acabados, los vidriados se realizan en blanco, verde, melado y transparente para las marmitas, apareciendo también fórmulas mixtas del tipo verde con manganeso (que no debe ser relacionado con las cerámicas con estas características del s. X) o marrón para algún fragmento de marmita. Entre las decoraciones, son frecuentes los trazos pintados con almagra o con manganeso en las formas jarro/a y jarrito/a, aunque no podamos precisar nada más por lo fragmentario del material.
En lo referido a la forma marmita, casi todos los fragmentos localizados se corresponden con formas similares a las descritas para la UEI29, con fondos indicados ligeramente convexos, cuerpos de tendencia globular y bordes rectos de tendencia troncocónica o cilíndrica, cocciones oxidantes y pastas finas, que se fechan genéricamente en la primera mitad del s. XIII.

Sin embargo, el principal problema de índole cronológico observable en esta unidad es la presencia de la forma ataifor de labio triangular con un vedrío melado oscuro compacto al interior y bastante degradado en el exterior de la pieza (CPE/200 I/I33/4), dadas las observaciones que hice constar a propósito de este tipo de decoración para piezas similares localizadas en la UE- 127. Cabe añadir aquí que se trata, empero, de una forma bien conocida en el repertorio cerámico andalusí (ROSSELLÓ-BORDOY, 1978b) que se suele fechar en la primera mitad del s. XIII.

En mi opinión, si atendemos a la posición estratigráfica del conjunto y teniendo en cuenta las características generales de los materiales, creo bastante plausible una datación para los mismos centrada entre el primer y el segundo cuarto del s. XIII.

\section{UE- I 34}

El muestreo estadístico efectuado con los materiales cerámicos localizados en esta unidad revela unas proporciones del 95\% para los materiales facturados a torno, frente al 5\% facturados a mano/torno lento. Proporciones similares se obtenían en el muestreo estadístico realizado sobre los materiales exhumados en los niveles inferiores de la c/Ericas (sobre todo, UE-II/I303) (BELLÓN AGUILERA y MARTíNEZ SALVADOR, 1999b). Cabe destacar, en estos porcentajes, la ausencia de grandes contenedores u otro tipo de producciones cuyas características específicas de facturación y subsiguientes observaciones, ya han sido descritas con anterioridad, observándose excepcionalmente para esta unidad una distribución del 100\% de las producciones facturadas a mano/torno lento en la forma marmita, cuyas características describiremos más adelante. 
En cuanto a las cocciones, es interesante constatar de nuevo un cierto equilibrio entre las denominadas como oxidantes (47\%) frente a las llamadas reductoras (37\%), siendo el $16 \%$ el porcentaje relacionado con las cocciones mixtas, dominando el primer las cocciones oxidantes y mixtas en las formas ataifor, orza y marmita, y las segundas en las formas jarrito/a.

En lo referido a los acabados, los vidriados se realizan en blanco, melado-manganeso y transparente o verdoso para las marmitas. Entre las decoraciones, aparecen también trazos pintados al manganeso en las formas jarro/a y jarrito/a.

Quizás el dato más sigificativo para este conjunto cerámico lo proporciona la asociación de las formas candil de cazoleta abierta y marmita, esta última con dos producciones diferentes técnica y formalmente: una producción a) representada con porcentajes del $26 \%$ del total de fragmentos cerámicos exhumados, facturados a torno y asimilables a las marmitas descritas para los niveles inmediatamente superiores. Una producción b) con porcentajes del $74 \%$, y caracterizada por ser un tipo ya descrito para los niveles de la primera mitad de s. XIII (ROSSELLÓ-BORDOY, 1978a) de factura a mano/ torno lento, desgrasante medio y pasta rojiza, base plana, cuerpo de tendencia troncocónica y borde reentrante, acabadas al interior mediante vidriados transparentes, verdosos o marrones. Formas y asociaciones parecidas se localizaron en contextos estratigráficos similares correspondientes a los niveles fundacionales de la $\mathrm{Cl}$ Ericas (UE-I I/ I 303 y I I/ / 66) (BELLÓN AGUILERA y MARTÍNEZ SALVADOR, 19995) fechados en los últimos años del s. XII o principios del s. XIII.

En cuanto a la forma candil de cazoleta abierta, el ejemplar localizado en esta unidad (CPE/200I/I35/19) se corresponde con los tipos antiguos de la serie, caracterizados genéricamente por la tendencia reentrante de los bordes de la cazoleta, y que se suelen fechar a finales del s. XII, principios del s. XIII (AZUAR RUIZ, I98। y 1985).

En mi opinión, si atendemos a la posición estratigráfica del conjunto y teniendo en cuen- ta las características generales de los materiales, creo bastante probable una datación para los mismos centrada entre el primer y segundo cuarto del s. XIII.

\section{UE- I 35}

Las características específicas de las producciones cerámicas localizadas en esta unidad, así como la ausencia de producciones y formas con necesidades particulares de facturación, implican unas proporciones del 100\% para el apartado de cerámicas facturadas a torno.

En lo referido a los acabados, los vidriados se realizan en blanco, verde y melado o melado-manganeso, siendo de nuevo transparente o verdoso para las marmitas. Los tipos cerámicos son similares a las descritos para las producciones de UUEE anteriores, por lo que no voy a insistir aquí sobre ello.

El hallazgo más significativo es el de un candil de cazoleta abierta, de carácterísticas similares al descrito anteriormente, pero en mejor estado de conservación (CPE/200|/|35/21).

Dadas las características propias de esta unidad y las observadas a propósito de los depósitos precedentes, así como las características generales de los materiales, creo bastante probable una datación para los mismos centrada entre el primer y segundo cuarto del s. XIII.

\section{UE- I 38}

Los materiales cerámicos localizados en esta unidad no parecen mostrar grandes variaciones respecto de los resultados estadísticos obtenidos con el muestreo del conjunto cerámico localizado en la UE- I34, si bien parece existir un cierto incremento en lo que se refiere al apartado de las facturaciones, donde se observan unas proporciones del 90\% para los materiales facturados a torno, frente al 10\% facturados a mano/torno lento, lo que, como ya se ha comentado, guarda cierta similitud con los muestreos estadísticos realizados sobre los materiales exhumados en los niveles inferiores de la c/Ericas (sobre todo, UE-III/ I 66) (BELLÓN AGUILERA y MARTÍNEZ SALVADOR, 1999b). 
En cuanto a las cocciones, es interesante constatar de nuevo el relativo equilibrio entre las denominadas como oxidantes (45\%) frente a las llamadas reductoras (55\%), sin que se hallan detectado cocciones mixtas, aunque el conjunto -como los anteriores- no es demasiado extenso.

La forma marmita, como hemos dicho, aparece mayoritariamente facturada a mano/torno lento, con un tipo de producción equiparable a la descrita como b) para la UE- 134, si bien hay que dejar constancia de que aparece asociada a otro tipo de marmita facturada a torno cuya pasta de tonos rojizos se sitúa, en cuanto al grosor, a medio camino entre las producciones a torno características de mediados del s. XIII y el tipo de producciones anteriormente mencionado.

También fue localizado un fragmento de jarrito/a con decoración esgrafiada de pasta ligeramente más gruesa que la de los ejemplares anteriores (CPE/200I/I38/5), si bien no es posible establecer distinciones tajantes entre este fragmento y el localizado en la UE-I 35 (CPE/200I / / 35/ / 2), perteneciendo ambos fragmentos a un tipo genéricamente encuadrado en la primera mitad del s. XIII.

Por último, el fragmento que hemos identificado como adscribible a la forma orza (CPE/200 //I38//3), vidriado en verde, mantiene similitudes formales con tipos parecidos de jijona (AZUAR RUIZ, 1985), Calatrava la Vieja (ZOZAYA, Ed., 1995) y Murcia (NAVARRO, 1991), con cronologías centradas en los momentos finales del s. XII y principios del s. XIII.

En resumen, teniendo en cuenta las características de los materiales y su posición estratigráfica, pienso como relativamente aceptable proponer una datación para los mismos centrada entre el primer cuarto del s. XIII o finales del s. XII.

\section{CONCLUSIONES}

De lo que se trataba era de evaluar la coherencia y homogeneidad de este conjunto de materiales atendiendo principalmente a su localización metodológica, es decir, a su proceden- cia estratigráfica o de prospección arqueológica, sin desplazar el eje principal del trabajo a ese tipo de estudios que, heredados del anticuariado y la Historia del Arte, atienden sobre todo a las piezas "singulares" (JIMÉNEZ CASTILLO, et alii, 1997) de cada conjunto material, basando su metodología más en el reconocimiento de las similitudes y paralelismos derivados de comparaciones formales y estilísticas entre elementos aislados de su propio registro arqueológico (cuando lo tienen), que en la propia lógica científica de la Arqueología. A pesar de lo que se ha llegado a afirmar en alguna ocasión (NAVARRO PALAZÓN et alii, 1989), en Arqueología las cronologías deben tener en cuenta las leyes de sucesión estratigráfica y, por tanto, cualquier "aproximación" cronológica debe basarse en los resultados obtenidos mediante el análisis de los datos aportados por la estratigrafía, por muy simple que ésta pueda parecerle al profesional encargado de la evaluación de los restos.

Por último, creo que los interesantes resultados obtenidos a nivel estratigráfico con la realización del sondeo efectuado en la Capilla del Palacio Episcopal, esto es, la localización y documentación de todo un conjunto de niveles sellados que podemos datar provisionalmente entre los SS. XII-XIII, para el nivel inferior (UE138) y los SS. XIII-XIV para los niveles superiores (UE 109 y 105), deberían completarse con el estudio mediante técnicas de laboratorio de los materiales arqueológicos localizados. Es obvio que un estudio de tales características desbordaba por completo los límites presupuestarios y temporales propuestos para la ejecución del sondeo, sujeto a la legislación actual y a la propia dinámica de mercado en la que se inserta la Arqueología Urbana, dinámica cuyos exiguos márgenes económicos de actuación para el desarrollo de los trabajos de investigación, se suple, en muchos casos, con un exceso de voluntarismo por parte de los profesionales de la arqueología. Por lo tanto, y en ausencia de los datos descritos con anterioridad, debemos considerar provisionales las propuestas cronológicas realizadas; propuestas que, por otra parte, no hacen sino ampliar y confirmar, también para la ciudad de Murcia, las interesantes perspectivas abiertas por los trabajos de R. Azuar para el área alicantina (Vid. bibliografía). 


\section{BIBLIOGRAFÍA}

AMIGUES, E; MESQUIDA, M.; SOLER, M. (199I): "La cerámica esgrafiada en los talleres mudéjares de Paterna (Valencia)". IV Coloquio Internacional de la Cerámica Medieval del Mediterráneo Occidental, Lisboa, 1987.

AMORES LLORET, R. (|99|): "Maquetas arquitectónicas islámicas de Murcia", Verdolay, 3.

AZUAR RUIZ, R. (198I): "Algunas notas sobre el candil de cazoleta abierta y de pellizco, hispanomusulmán), II CMMO.

- (1985) Castillo de la Torre Grossa (lijona), Alicante.

AZUAR RUIZ, R. (Dir.) (1994): El Castillo del Rio (Aspe, Alicante). Arqueología de un asentamiento andalusí y transición al feudalismo (siglos XII-XIII), Alicante.

AZUAR, R; BORREGO, M; MARTI, J.; NAVARRO, C; PASCUAL, J.; SARANOVA, R; BURGUERA, V.; GISBERT, J.A. (1995): "Cerámica tardo-andalusí del País Valenciano (Primera mitad del siglo XIII)". V CICMMO, Rabat.

AZUAR, R.; MARTÍ, J.; PASCUAL, J. (1998): La Castell d'Ambra (Pego). De las producciones andalusíes a las cerámicas de la conquista feudal (siglo XIII), págs. 279- 30l.

BAllANA, A. (1979): "Céramiques médiévales: les méthodes de la description analytique appliquées aux productions de l'Espagne Orientale", Melánges de la Casa de Velázquez, XV. Págs. | 35- 185.

- (1980) "Céramiques médiévales: les methodes de la description analytique appliquées aux productions de I'Espagne Orientale. II Les poteries decorées", Melánges de la Casa de Velázquez, XVI, Págs. 57-95.

BELLÓN AGUILERA, J. (200 I): "Un sondeo estratigráfico en la Capilla del Palacio Episcopal: reflexiones sobre la estratigrafi'a del S. XIII en la ciudad de Murcia". E. P.

BELLON AGUILERA, J.; MARTíNEZ SALVADOR, C. (1999a): "Un conjunto religioso en el Campo de Cartagena. Primeros datos para un estudio sobre la religiosidad en el ámbito rural durante el siglo XIII", V CAME, págs. 449-458, Valladolid.

- (1999b) "Excavación arqueológica de urgencia C/EricasC/San Luis Gonzaga (Murcia)". En preparación.

- (1999c) "Ampliación de la excavación de urgencia de El Pocico II. La campaña de 1999". En preparación.

BERNABÉ GUILLAMÓN, M. (1 990a): "La muralla medieval del Pasaje de Zabalburu (Murcia)". Memorias de arqueología, 5, Murcia. Págs. 435-47I.

- (1990b) "Un reposadero con fachada arquitectónica en la calle Raimundo de los Reyes de Murcia", Verdolay, 2. pp. 249-254.

BERNABÉ GUILLAMÓN, M.; MANZANO MARTÍNEZ, J.; RUIZ PARRA, I.; SÁNCHEZ PRAVIA, J. A. y MUÑOZ CLARES, C. (1994): "Excavaciones arqueológicas en la Escuela Superior de Arte Dramático y Danza. Antiguo seminario conciliar de san Fulgencio", Memorias de Arqueología, 9, Murcia.
FUENTES Y PONTE, J. ( 1872): (Reimp. 1980) Murcia que se fue, Murcia.

GARCÍA BLÁNQUEZ, LA.; MARTÍNEZ RODRÍGUEZ, A.; MARTÍNEZ SÁNCHEZ, C. (199|):"La Torre Islámica "Casa del Obispo", Lorca (Murcia)". Memorias de arqueología, 6, Murcia.

GARCÍA CANO, J.M.; MANZANO MARTÍNEZ, J. (199|): "Un lote de cerámica de Manises y vidrio de Castril (ss. XVII-XVIII) aparecido en la ciudad de Murcia. Estudio analítico de sus materiales". Verdolay, 3, Murcia.

GARRIDO I VALLS, J. D. (1997): Jaume I i el regne de Múrcia, Barcelona.

GISBERT SANTOJA, J.A.; BURGUERA SANMATEU, V.; Y BOLUFER I MARQUES, J. (1992): La cerámica de Daniya -Denia-. Alfares y ajuares domésticos de los siglos XII- XIII, Valencia.

GUTIÉRREZ LLORET, S (1996): La Cora de Tudmir. De la Antigüedad tardía al mundo islámico. Poblamiento y cultura material. Madrid-Alicante.

JIMÉNEZ CASTILLO, P.; NAVARRO PALAZÓN, J:; COLL CONESA, J. y BARRACHINA, J. (1997): Sobre cuatro casas andalusíes y su evolución (Siglos X-XIII). Murcia.

MARTÍNEZ RODRÍGUEZ,A; MONTERO FENOLLÓS, J. L. (1989): "Testar islámico de la C/ Galdo (Lorca)". Memorias de Arqueología, 4.

- (1990): "La qubba islámica de la calle Cava nII, Lorca". Memorias de Arqueología, 5.

MOLINA MOLINA, A. L. (1989): El Campo de Murcia en el siglo XV. Murcia.

NAVARRO PALAZON, J. (I 986a): La cerámica esgrafiada andalusí de Murcia, Madrid.

- (1986b) La cerámica islámica en Murcia. Volumen I: catálogo, Murcia.

- (1990) "Los materiales islámicos del alfar antiguo de San Nicolás de Murcia", Fours de potiers et "testares" médiévaux en Méditerranée Occidentale, Madrid, 1990.

- (199I) Una Casa islámica en Murcia. Estudio de su ajuar (siglo XIII), Murcia.

NAVARRO PALAZON, J. y JIMÉNEZ CASTILLO, P. ( 1995): "Maquetas arquitectónicas en cerámica y su relacion con la arquitectura andalusi", Casas y Palacios de al- Andalus. Siglos XII-XIII, Madrid.

NAVARRO PALAZÓN, J.; ROBLES FERNÁNDEZ, A. (1989): "El baño árabe de San Nicolás de Murcia. Memoria preliminar", Memorias de Arqueología, 4.

NAVARRO POVEDA, C. (1990): Excavaciones arqueológicas en el Castillo de la Mola (Novelda, Alicante). Las cerámicas comunes (s. XIV-XV). Alicante.

ROSSELLÓ-BORDOY, G (1978a): "La céramique arabe á Majorque (Problémes chronologiques)", I CMMO, Valbonne. 
- (1978b): Ensayo de sistematización de la cerámica árabe en Mallorca. Palma de Mallorca.

ROSSELLÓ PONS, M (1983): Les cerámiques almohades del Correr de Zavelló. Ciutat de Mallorca. Palma de Mallorca.

SÁNCHEZ GONZÁLEZ, Ma J. (1990): "Excavaciones arqueológicas de urgencia en el recinto fortificado medieval de Molina de Segura". Memorias de Arqueología, 5.
TORRES FONTES, J. (1963): "Documentos de Alfonso $X$ el Sabio. El recinto urbano de Murcia musulmana", CODOM, I, Murcia.

ZOZAYA, J. (1995): Alarcos '95, El fiel de la balanza, Toledo. 


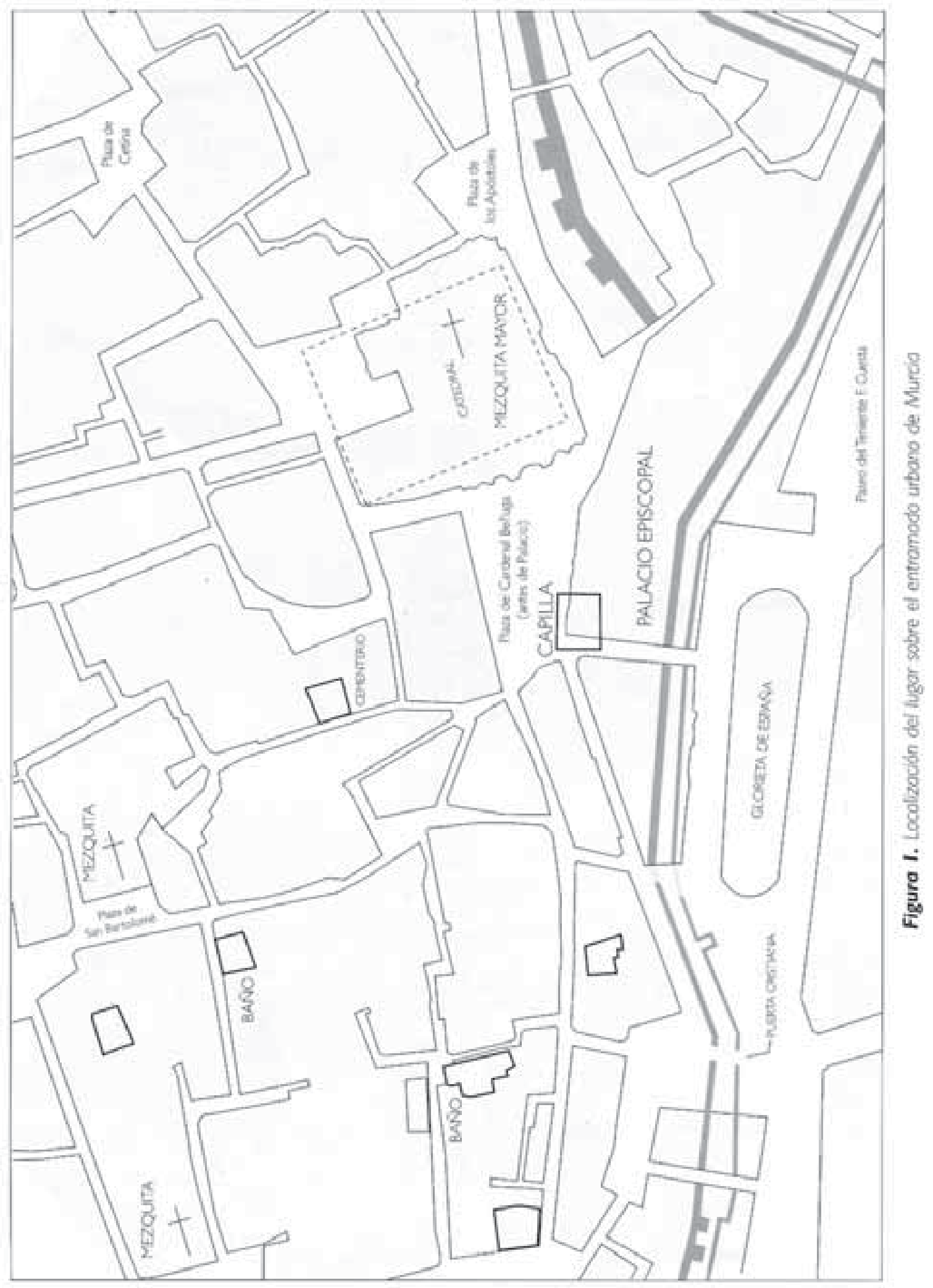




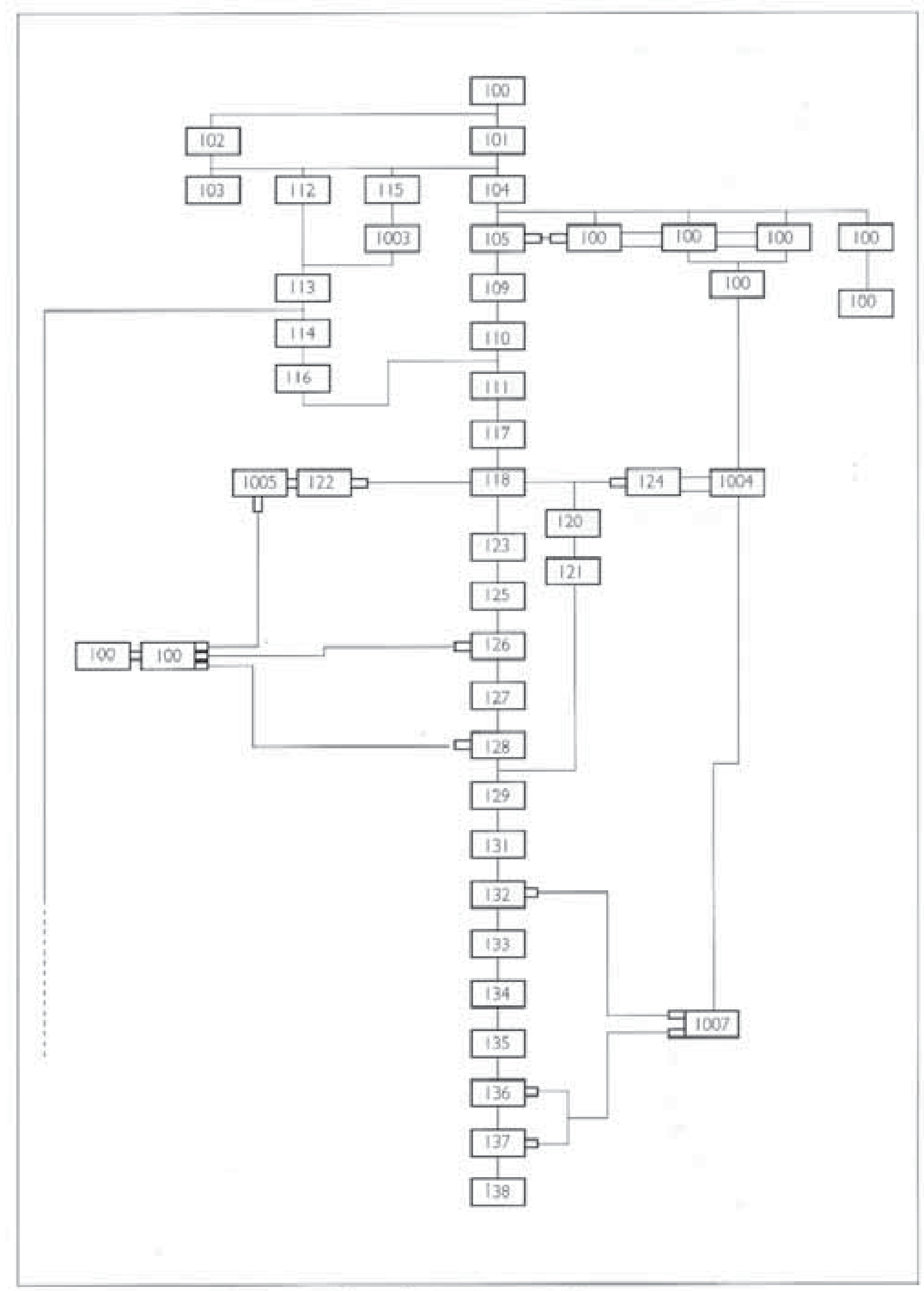

Figura 2. Secuencio estratignufico 


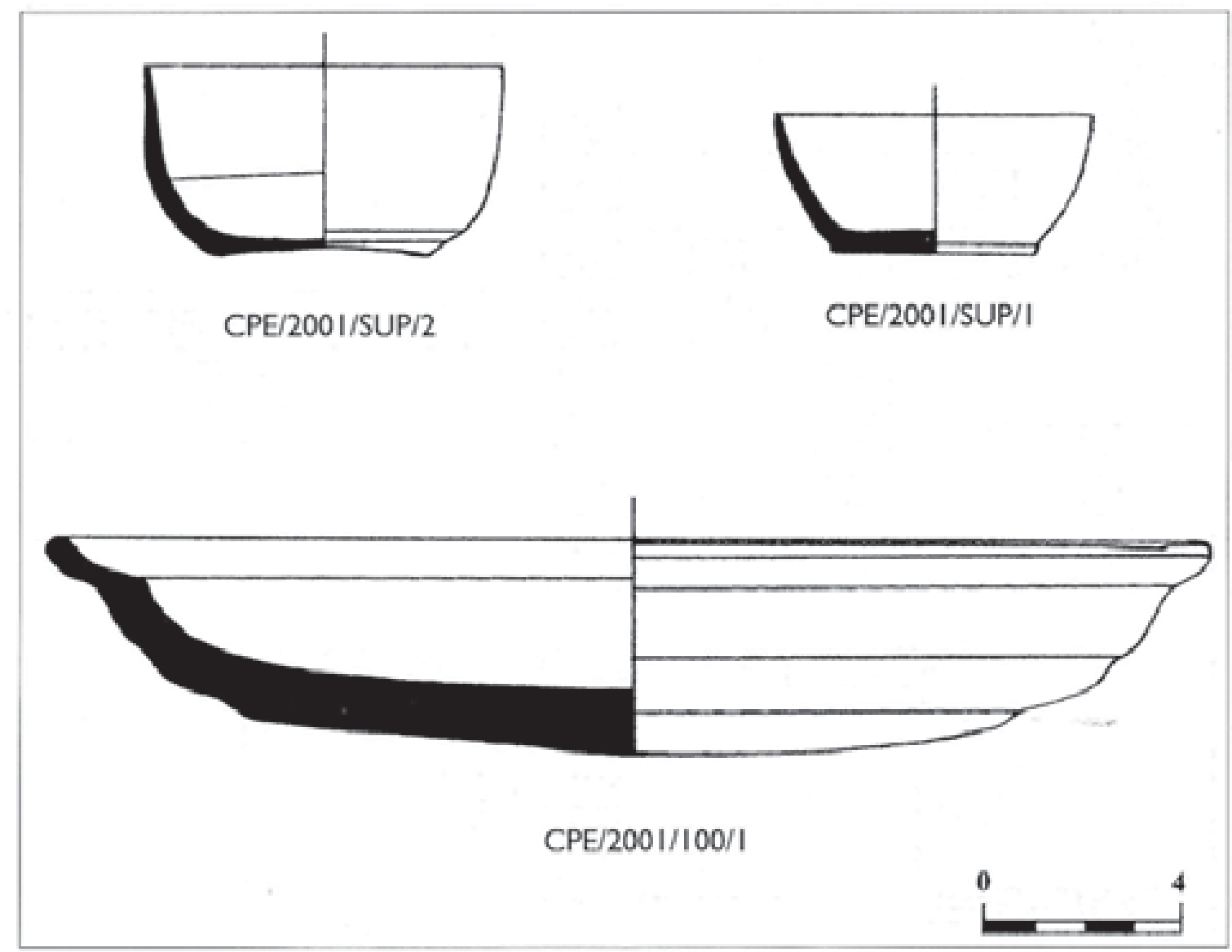

Figura 3. Materiales superficiales y UE-100

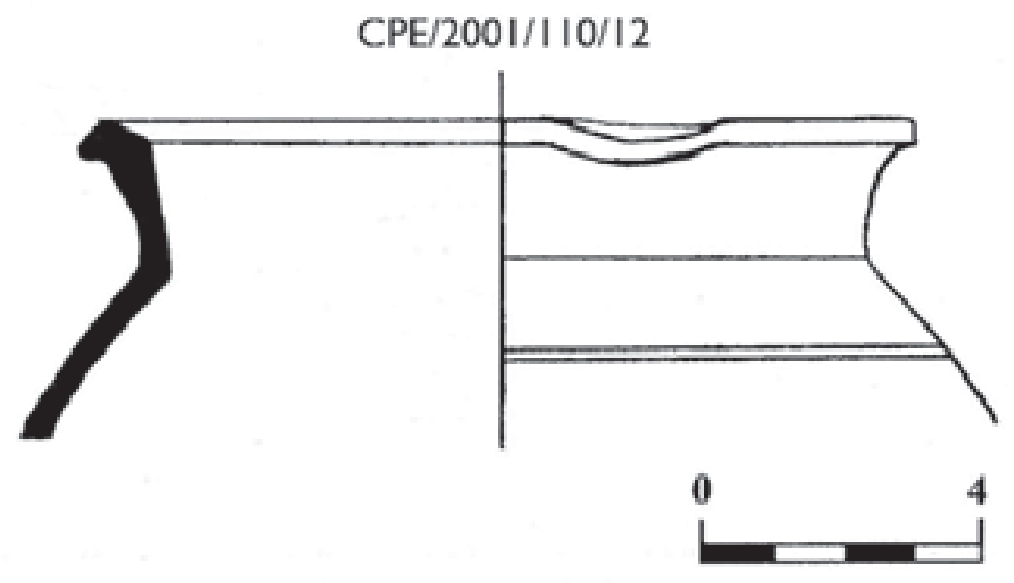

Figura 4. Materiales UE-100 


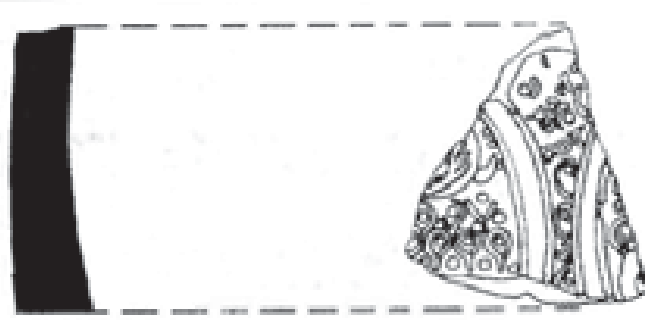

Figura 5. Materiales UE-127

CPE/200I//27/30

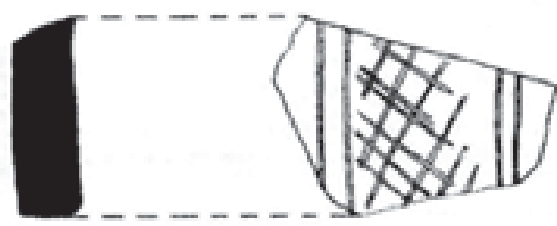

CPE/2001//27/32
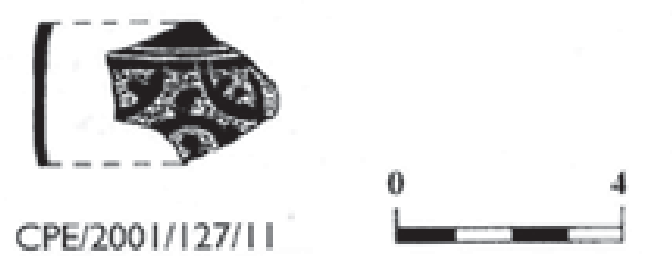

Figura 6. Materiales UE-129 y 131

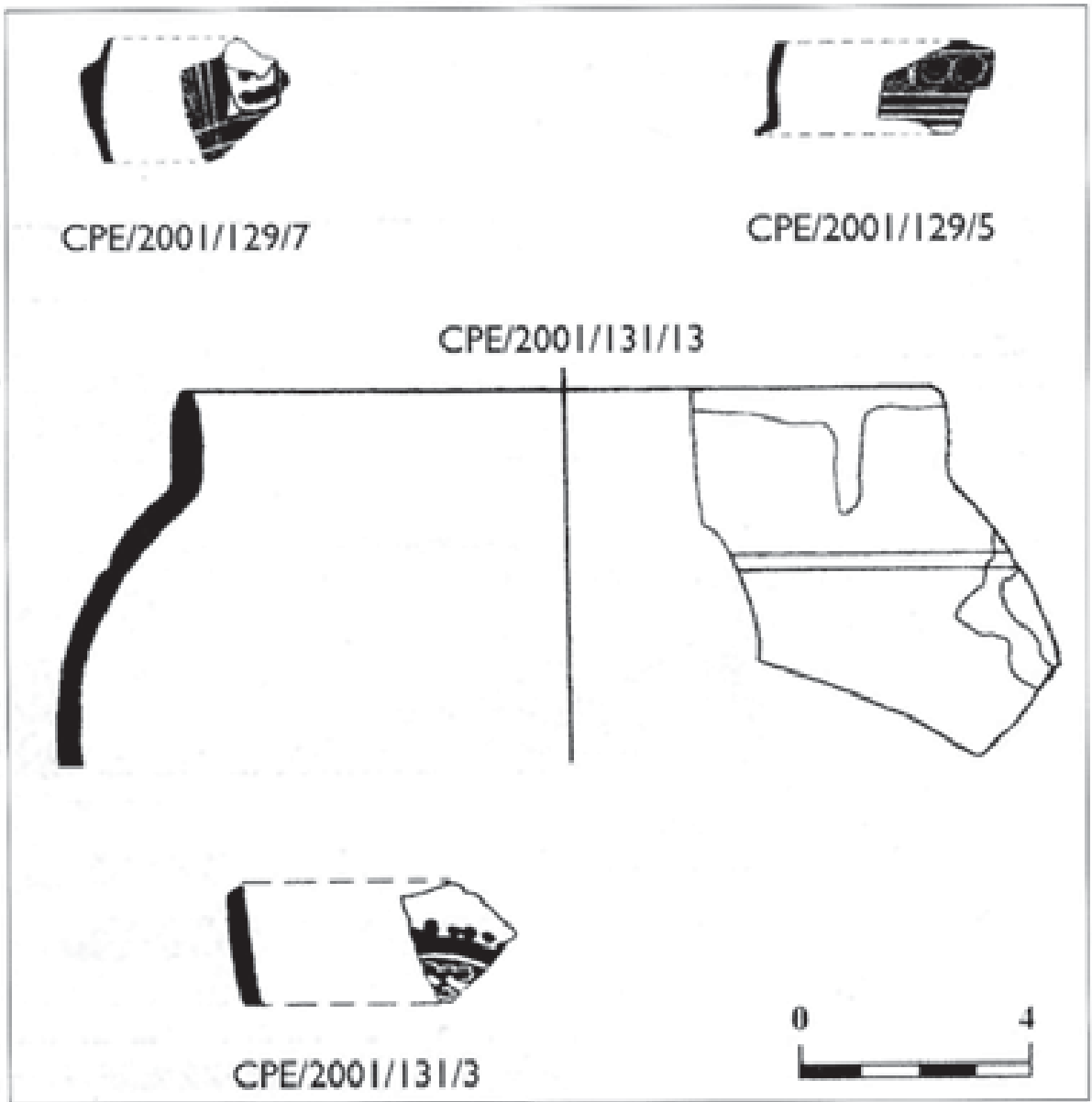




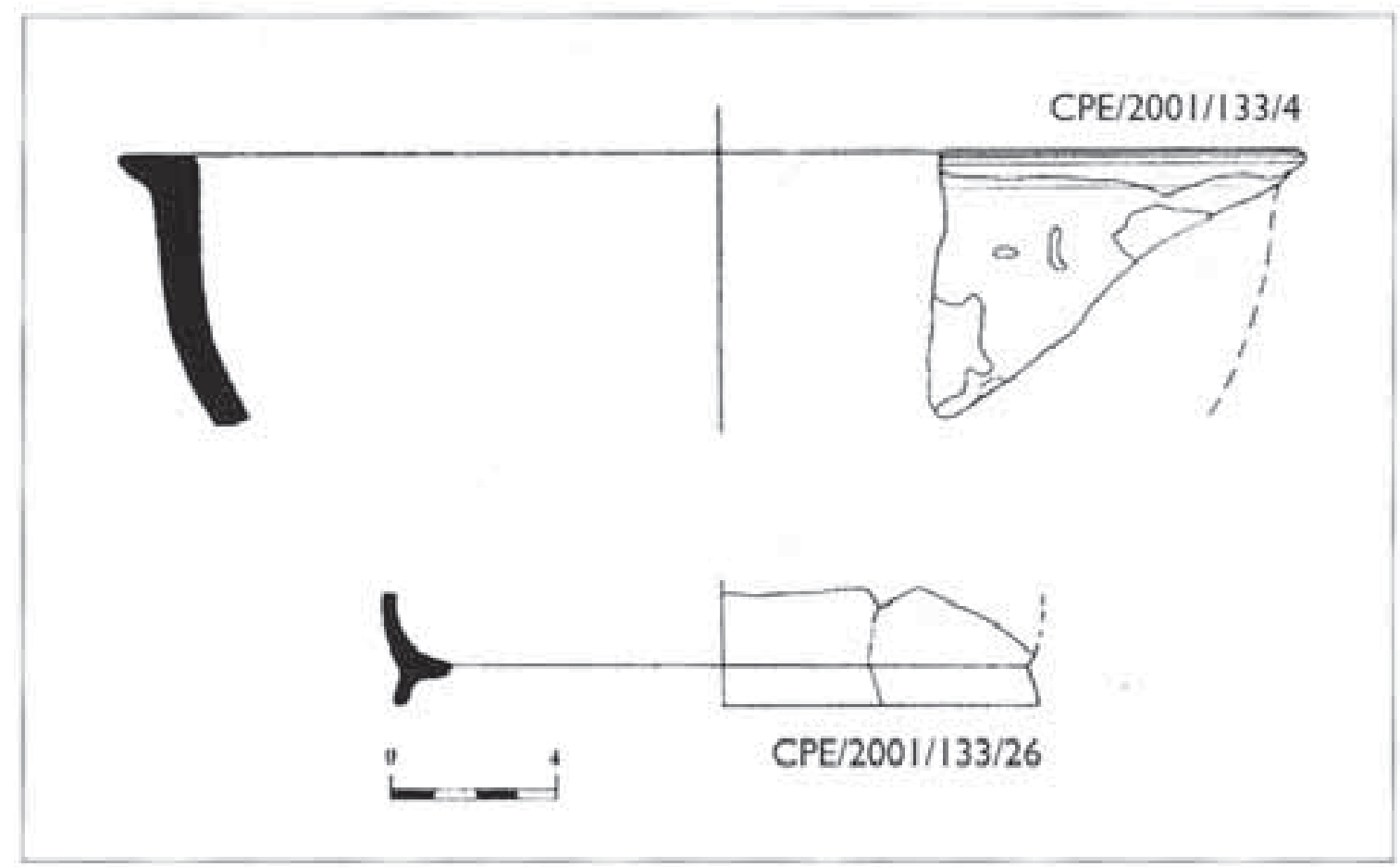

Figura 7. Materiales UE-133

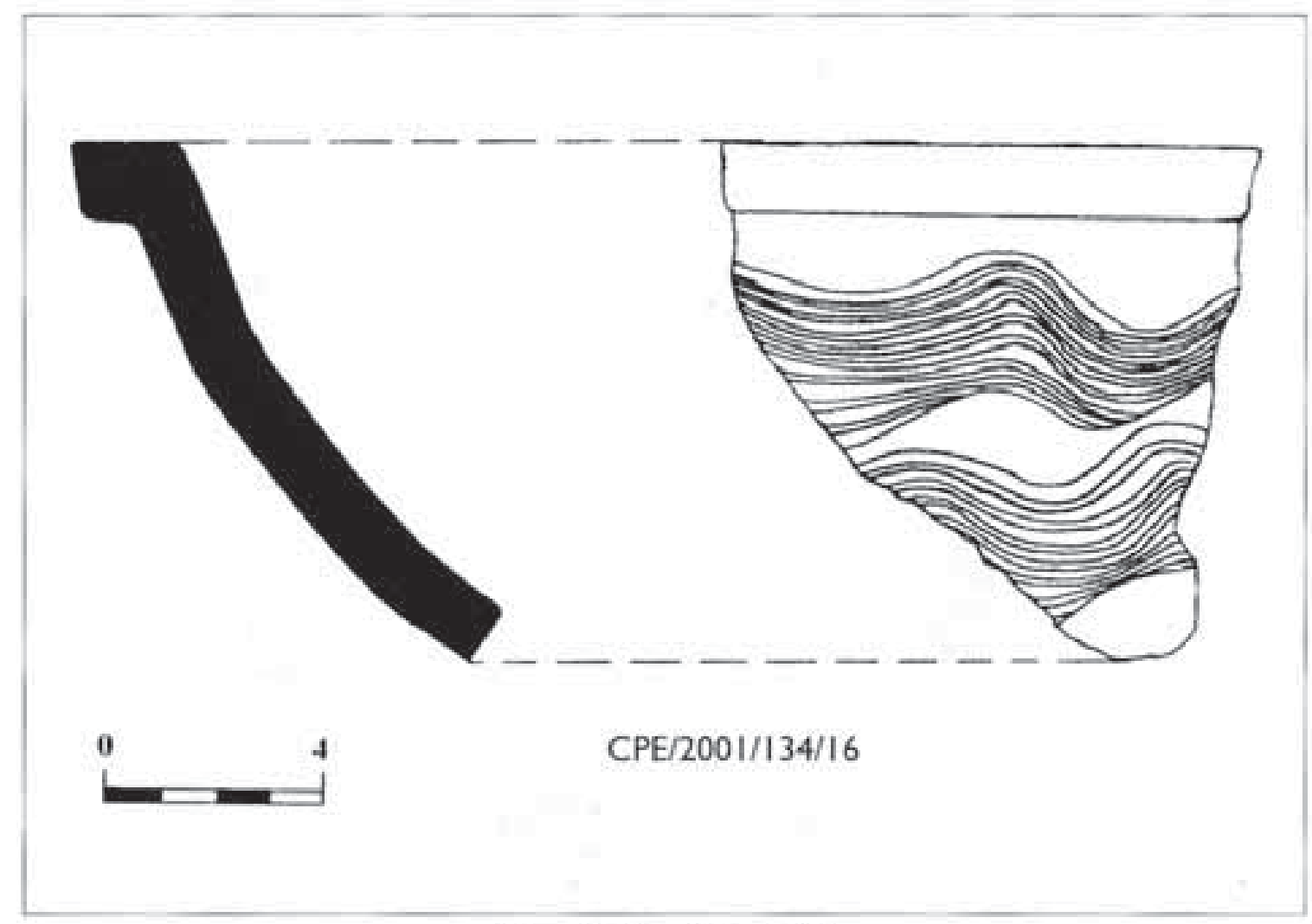

Figura 8. Materiales UE-134 


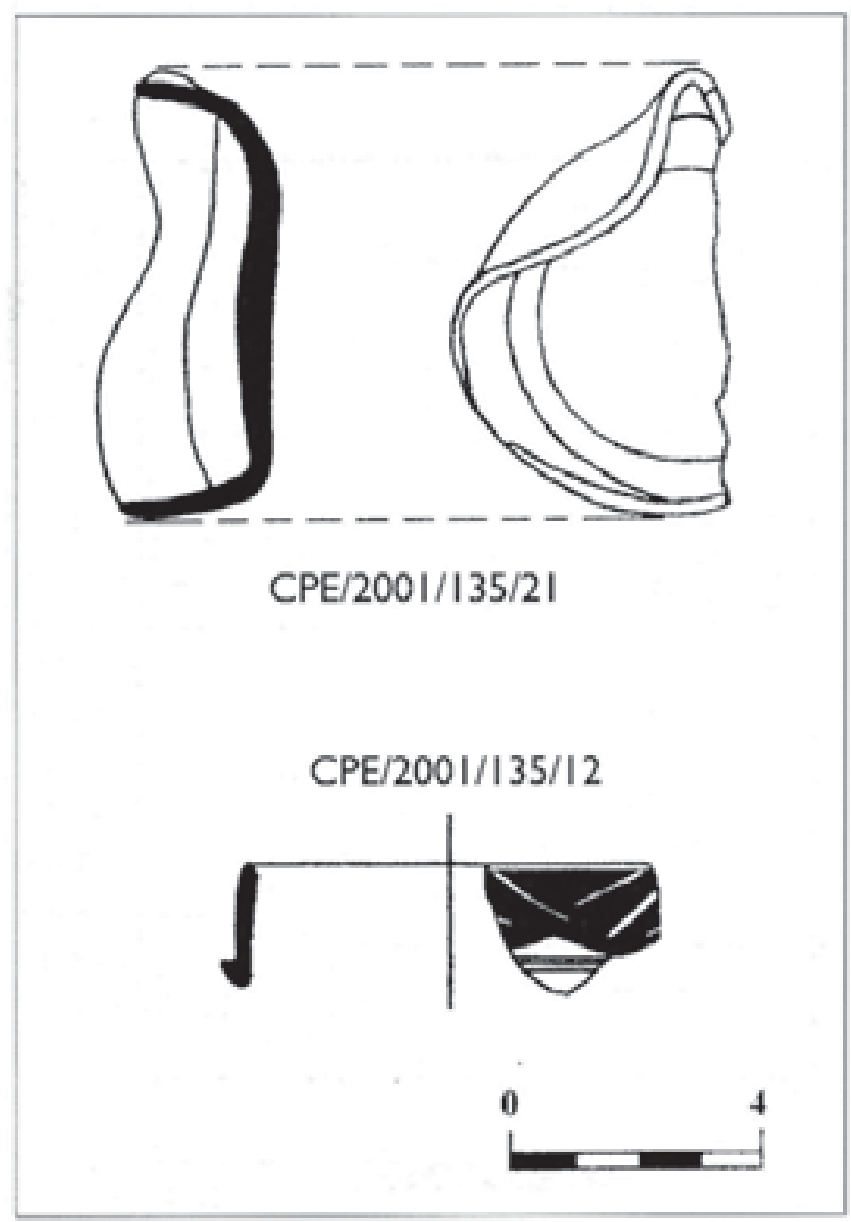

Figura 9. Materiales UE-135

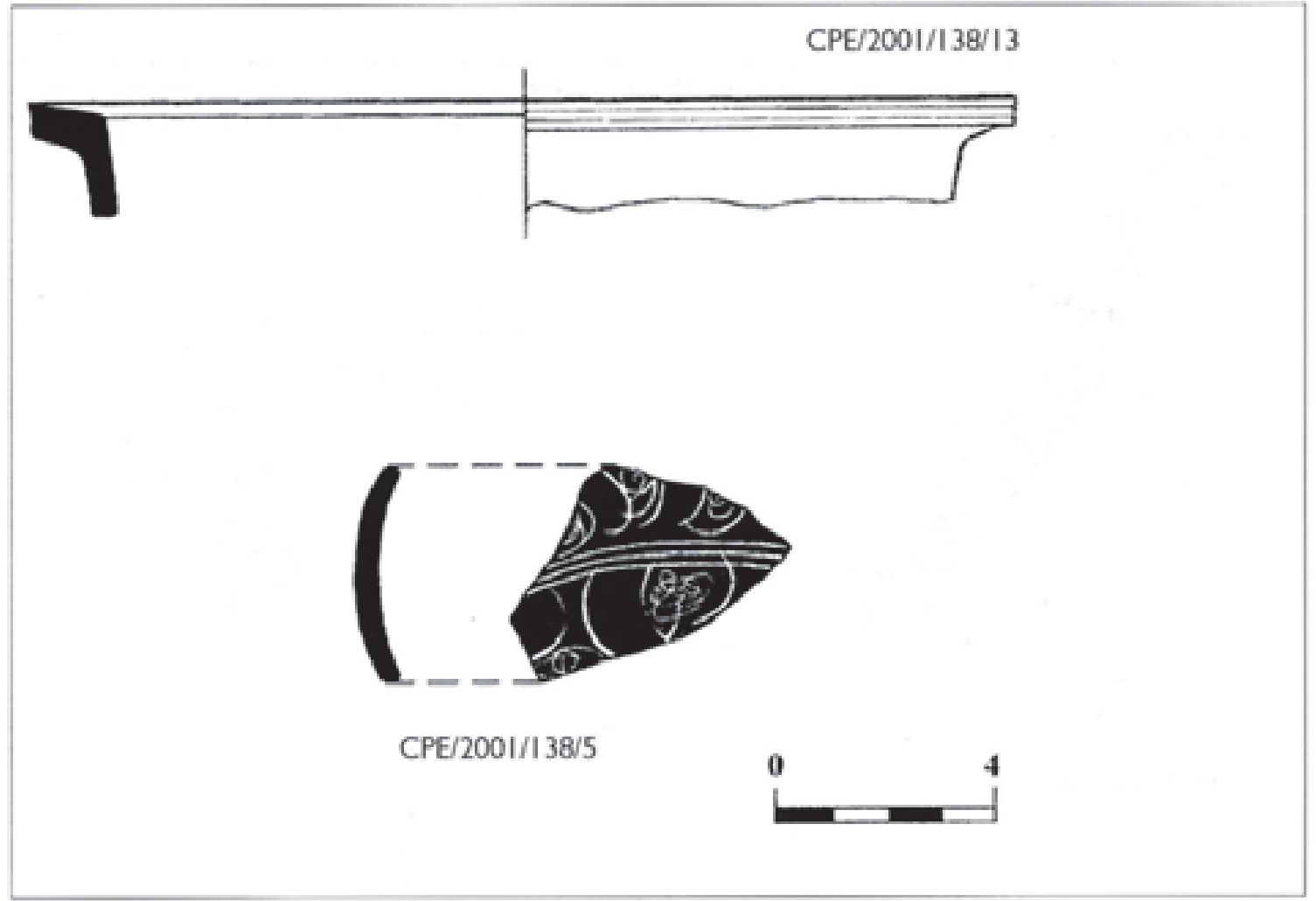

Figura 10. Materiales UE-138 


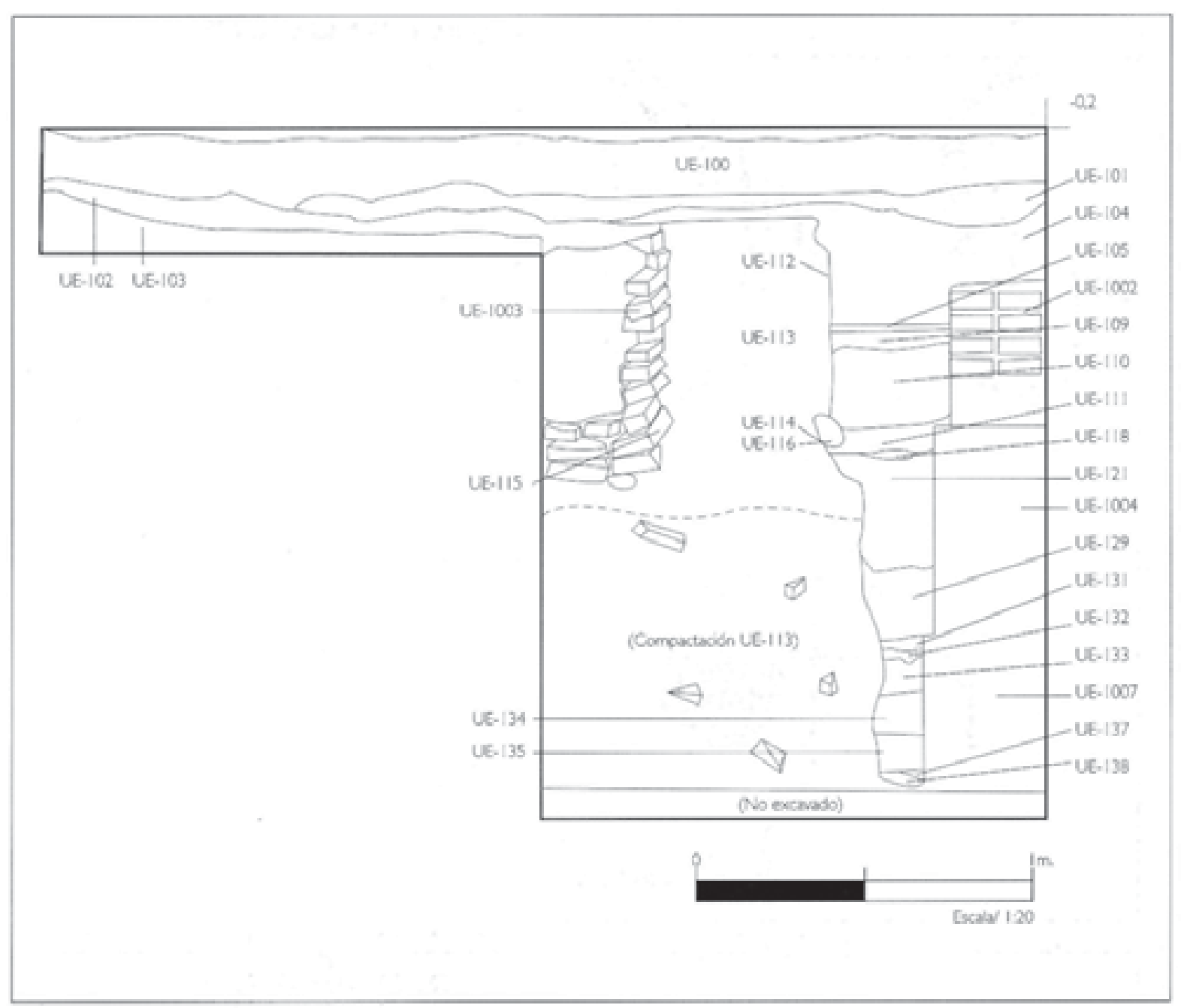

Figura II. Perfil Oeste 